\title{
Former Team Sports Experiences: Development of Collaborative and Leadership Skills for Future Hospitality Managers
}

\author{
James A. Williams \\ James Madison University, Harrisonburg, USA \\ Eric Brown, Robert Bosselman \\ Iowa State University, Ames, USA \\ Reginald Foucar-Szocki \\ James Madison University, Harrisonburg, USA
}

\begin{abstract}
Some hospitality firms thrive, because they have effective functional teams (e.g., front of the office (FOH) within a hotel and back of the house (BOH) within a restaurant) in their respective hospitality organizations. Functional teams can be viewed as structured teams in hospitality milieus. For functional teams to succeed, proper leadership needs to be implemented to inspire and to motivate employees to work cohesively towards a common goal. The purpose of this study was to examine team sports' impact on collaboration and leadership tactics among hospitality undergraduate students — our future hospitality managers and leaders within this diverse industry. The multifactor leadership questionnaire (MLQ) 5X short-form instrument was utilized to examine a convenience sample of 170 undergraduate students' leadership styles. The MLQ scoring key was used to determine that $64.1 \%$ of undergraduate students who participated in team sports developed successful leadership styles. Results also indicated that individuals with team sport experiences preferred to work in groups synonymous to hospitality firms.
\end{abstract}

Keywords: youth sports, multifactor leadership questionnaire (MLQ), work groups, diversity, team sports

\section{Introduction}

In America, team sports were designed and developed to build collaborative leadership skills among athletes performing in convoluted situations (Chelladurai \& Carron, 1983). Team sports can provide skills that hospitality managers need to inspire employees in today's diverse and complex work environments. Inspiring individuals who come from different cultures and who display unique personality traits can be challenging for inexperienced hospitality managers (Altinay, 2010). Because managing daily issues requires a collaborative effort in hospitality organizations, low-level team members and high-level team members are expected to be

James A. Williams, Ph.D., assistant professor, School of Hospitality, Sport, and Recreation Management, James Madison University.

Eric Brown, Ph.D., assistant professor, Apparel, Events, and Hospitality Management, Iowa State University.

Robert Bosselman, Ph.D., professor and chair, Apparel, Events, and Hospitality Management, Iowa State University.

Reginald Foucar-Szocki, Ph.D., professor, School of Hospitality, Sport, and Recreation Management, James Madison University.

Correspondence concerning this article should be addressed to James A. Williams, School of Hospitality, Sport, and Recreation Management, James Madison University, USA, 800 South Main St. MSC 2305, Harrisonburg, VA 22807, Godwin, Room 367; Phone: (540) 568-7667. Email: will22ja@jmu.edu. 
proactive when facing with internal and external challenges (e.g., high turnover, language barriers, or new technologies) (Altinay, 2010; Latham \& Vinyard, 2004). Collaboration and effective leadership can be employed to create proactive tactics for internal and external changes.

People tend to resist change, and this attitude can halt the positive progression of hospitality firms. Collaborative leaders are optimistic about the future and view change as an opportunity to build cohesive teams (Chrislip, 2002). The hospitality industry covers a wide spectrum of entities, such as lodging, restaurants, cruise lines, and sporting arenas. All these entities require hospitality managers with collaborative traits (e.g., building trust, embracing change, fostering continuous communication) to promote unified decision-making and commitment (Brymer, Wilborn, \& Schmidgall, 2006; Chrislip, 2002). In addition, some individuals might surmise that collaborative leadership emerges from past experiences within diverse environments.

Team sports foster collaborative leadership in unique environments that consist of individuals from various backgrounds (e.g., ethnic groups, religious practices, sexual preferences, or cultural upbringings) (Chelladurai, 1980; Altinay, 2010). Individualistic behavior derives from former experiences and complex situations that mimic similar experiences to produce beneficial outcomes (Nonaka \& Nishiguichi, 2001). Team sports give athletes a chance to effectively communicate team goals with a collective group of different athletes (Calhoun, 2007). Participation in team sports augments intuitive knowledge when team leaders attempt to manage individuals or teams during crisis situations (Arthur-Banning, Wells, Baker, \& Hegreness, 2009). Some business leaders consider team sports as the catalyst to develop collaborative tactics needed to manage complex teams and to develop a passion for working in cohesive work groups (Arthur-Banning et al., 2009). The purpose of this study was to examine team sports' impact on leadership traits and collaboration preferences amongst undergraduate hospitality students — our future hospitality managers and leaders within this diverse industry.

\section{Research Objectives}

The research questions central to this study focused upon examining how team sports affect undergraduate hospitality students' leadership tactics and desire to perform in work groups. The following research questions were used to guide the research study:

(1) Does team participation in team sports create a desire to work in collaborative work groups?

(2) Does participation in team sports prepare undergraduate hospitality students with effective leadership styles?

\section{Literature Review}

\section{Hospitality Managers}

Maon, Lindgreen, and Swaen (2009) reported that leaders must prepare to cater the needs and interests of teammates to promote collaboration within diverse work groups. Hospitality managers work in a unique industry, which requires leaders to have the ability to inspire and to motivate entry-level workers (e.g., individuals with high school education or low wage workers) to align behavior to team goals and objectives (Iun \& Huang, 2007). Hotel managers can find it challenging to promote cohesion among low-level employees due to their poor wages, long hours, and grueling work (i.e., managers find it difficult to motivate low-level employees) (Iun \& Huang, 2007; Ross, 1995). Therefore, hotel managers must be willing to inspire combative and diversified team members. 
Effective collaborative leaders have the ability to inspire followers to work towards common organizational goals (Stein, 2009), and hospitality requires managers who have leadership skills needed to motivate team members to toil towards a common goal. For example, restaurant managers are expected to perform efficiently and productively when attempting to align unique front of the house (FOH) and back of the house (BOH) team members (Lee \& Way, 2010). Delegating tasks, performing within structured and unstructured teams, and resolving issues among confrontational employees are significant leadership traits that managers need to flourish in the hospitality industry (Lee \& Way, 2010; Sugar \& Holloman, 2009). Hospitality work environments are becoming populated with diverse personnel, so hospitality leaders are required to exhibit collaborative skills that triumph in diverse work environments (Altinay, 2010). Problems can occur when hospitality managers are not well equipped with skills to manage change and to establish conditions that align individuals to common objectives.

When hospitality managers adjust their language and mannerisms to fit their employees' learning styles, the employees are inspired to embrace their management philosophies or change implementation strategies (Ross, 1995; Stein, 2009). For example, if hotel front desk managers smile while interacting with guests and team members, other team members might follow suit to create a cohesive work environment. Hotel managers who possessed collaborative teamwork skill sets can successfully control cohesive work milieus (e.g., housekeepers cleaning rooms together, front desk workers who are checking in guests) (Pudlowski, 2009). Hospitality managers should create objectives that direct team members as a cohesive unit rather than as selective individuals, because hospitality firms thrive as productive work teams (Latham \& Vinyard, 2004; Ross, 1995).

\section{Collaborative Leadership's Marriage to Team Sports}

Collaborative leadership has emerged as an advantageous global business approach to diverse work environments (Chrislip, 2002). Collaborative leaders are expected to utilize persuasive communication skills to establish trust among their internal and external teams; these leaders commit themselves to stimulating teammates towards common goals (Chrislip, 2002). Collaborative leadership forces individuals to embrace change; thus, collaborative leaders must be equipped with transparent communication skills to build confidence among constituents facing internal and external changes (Hinckley, 2009). Effective change management requires leaders who are willing to step out of their comfort zones while inspiring employees, to accept change initiatives (Hinckley, 2009).

Team sport leaders (e.g., coaches, team captains) are taught to align team members' behaviors and actions to the overall team vision to effectively manage constant change (Organization of Eastern Caribbean States, 2008). Team sports provide a structure for young athletes, because they learn the schedule and routines of practice to instill the concepts of team commitment in their leadership tactics (Organization of Eastern Caribbean States, 2008). Athletes develop a multitude of effective leadership tactics from team sports-intelligence, competitiveness, perseverance, and interpersonal skills-to ensure success in changing strategies in crisis situations (Manos, 2006). Manos (2006) argued that team sports teach individuals how to focus on the daily tasks within the team rather than other tasks not affecting the team's set objectives. Team sport leaders learn to remain flexible in leadership strategies to manage contingencies that impede team goals (Calhoun, 2007; Manos, 2006). 
Hospitality graduates are expected to manage processes, services, and contingencies in today's hospitality industry. With such an important mission, hospitality educators and industry leaders should seek to ensure that graduates embody effective leadership traits and tactics upon entering hospitality career fields. Hackett (2006) suggested that leaders who fail to use interpersonal skills to recognize and to appreciate followers might be ineffective in implementing change, because effective leaders inspired employees to be accountable for their behaviors and actions.

\section{Methods}

\section{Instrument}

This study used a constructed multifactor leadership questionnaire (MLQ) 5X short-form instrument that included a demographic section to collect data on respondents' ethnicity, gender, team sports participation, and preference for working in groups. Undergraduate hospitality students were grouped into three leadership categories: transformational, transactional, and passive leadership. The MLQ 5X short-form was used to distinguish respondents’ leadership styles.

\section{Data Collection}

The target population for this research study was undergraduate hospitality students who were attending a four-year hospitality degree program. Hospitality programs were identified using The Guide to College Programs in Hospitality, Tourism, \& Culinary Arts (International Council on Hotel, Restaurant, and International Education, 2011). Two schools were chosen with a convenience sampling technique to represent undergraduate hospitality students from the central federation. Hospitality program directors at each university were contacted by telephone to obtain their commitment prior to data collection.

Program directors volunteered to disseminate the surveys among their faculty, and their faculty delivered and collected the surveys among their students; 40 students were selected from a scheduled course at each institution so as to maintain consistency, while an additional 126 undergraduate hospitality students were randomly solicited to participate in this research study at both higher learning facilities. The scheduled course gathered respondents who were currently learning leadership competencies within that course; the other respondents were expected to learn those rudimentary skills throughout their hospitality management program experience.

\section{Data Analysis}

Data were imported into Statistical Package for Social Science (SPSS) version 19.0 to organize, code, and analyze the findings. Descriptive statistics were used to identify the characteristics of the demographic variables. Respondents' leadership styles were assessed in accordance with the MLQ instrument manual; the scores from the item responses were tallied and divided by the number of items that made up the scale. The chi-square statistic determined whether respondents who participated in team sports preferred working in groups or exhibited transformational leadership styles when compared with respondents who chose not to participate in team sports.

\section{Results}

There were 198 surveys collected from two Midwestern institutions to produce a 96\% response rate. At each institution, instructors hand delivered surveys to undergraduate students in assigned hospitality courses 
and then collected and returned them to the researcher. Twenty-eight surveys were discarded for two reasons: students who did not participate in youth sports or students who failed to complete the questionnaire in its entirety. This process resulted in an 82.5\% response rate of usable surveys, 170 out of the targeted 206 respondents. Paper-and-pencil surveys typically produce a higher response rate than web-based surveys (Dillman, 2007).

\section{Demographics of Respondents}

Table 1 displays the demographic information of respondents. Overall, $64.1 \%$ of the sample had team sport experience, and 35.9\% had individual sport experience. In America, team sports are used by millions of families relying on team sports to build collaborative skills and a desire to work with others in their children (Assegid, 2009; Seefelt, Ewing, \& Brown, 1996). This finding contributes to the high number of respondents who fell into the team sports participation demographic segment.

Table 1

Demographics of Undergraduate Hospitality Students $(N=170)$

\begin{tabular}{lcl}
\hline Sports participation & $N$ & $\%$ \\
\hline Team sports & 109 & 64.1 \\
Individual sports & 61 & 35.9 \\
\hline Gender & $N$ & $\%$ \\
\hline Male & 56 & 32.9 \\
Female & 114 & 67.1 \\
\hline Ethnicity & $N$ & $\%$ \\
\hline Caucasian & 147 & 86.5 \\
African American & 9 & 5.3 \\
Asian & 4 & 2.4 \\
Hispanic & 9 & 5.3 \\
Other & 1 & 0.5 \\
\hline Working preference & $N$ & $\%$ \\
\hline Work individually & 88 & 51.8 \\
Work as a group & 82 & 48.2
\end{tabular}

Horton, Foucar-Szocki, and Clark (2009) examined academic performance among undergraduate hospitality management students, and their sample population favored females (65\%) over males (35\%). The distribution in gender was similar in the current study with $67.1 \%$ females and $32.9 \%$ males, indicating that today's hospitality undergraduate programs in American universities appeal more to females than males. There were significant disparities among the different ethnic groups that participated in this research study. Caucasians made up $86.5 \%$ of the sample population, African Americans 5.3\%, Hispanics 5.3\%, Asians 2.4\%, and other (Africans) accounted for 0.5\%. According to the National Center for Education Statistics (2011), Caucasians account for 62.3\%, African Americans 14.3\%, Hispanics 12.5\%, Asians 6.5\%, and other 4.4\% of students enrolled in today's degree programs.

Team sports are structured to provide a social and competitive outlet for individuals and to promote character-building activities and cohesion among talented individuals in complex situations (Seefelt et al., 1996). This may be the reason why the majority of the sample participated in team sports and why more team-oriented sports dominate today's youth sport leagues. Overall, working preference proved to be indicative 
of respondents who participated in team sports, as seen in Table 2. The odds ratio was calculated with group work preference treated as the positive outcome. The odds ratio of 50.91 was statistically significant, $z=6.24$, and $p<0.0001$, indicating that those who participate in team-based youth sports were 50.91 times more likely to prefer working in groups.

Table 2

Cross-Tabulation of Sport Classification and Work Preference

\begin{tabular}{llll}
\hline \multirow{2}{*}{ Sport classification } & \multicolumn{3}{c}{ Work preference } \\
\cline { 2 - 4 } & Group & Individual & $71.49^{*}$ \\
\hline Team & 79 & 30 & \\
Individual & 3 & 58 & \\
\hline
\end{tabular}

Note. ${ }^{*} p<0.001$.

Since teams and groups are important to success in the hospitality industry (Pudlowski, 2009) and those who participate in team sports are more likely to prefer working in groups, it is important to determine the leadership style of those who participate in team-based sports. In this study, MLQ was used to assess and identify leadership styles of undergraduate hospitality students. Dependent variables associated with an undergraduate leadership style were collected through the application of the MLQ 5X self-rater form. Respondents answered queries from the MLQ 5X self-rater form, and specific queries were grouped together and scored. The MLQ uses a Likert-scale ranging from 0 to 4 ( $0=$ not at all; $4=$ frequently, if not always). When two leadership styles received a score of three or higher, the individual exhibiting two leadership styles was assigned the style with the higher score. Two leadership styles with the same averaged scores defaulted to the leadership style with the most scales. For example, the scores were totaled in the initial row, $(2.75)+(3.75)$ $+(3.5)+(2.5)+(3.5)=16 / 5=3.2$ overall score. This score falls within the range of 3.0-4.0, and this respondent was assigned transformational leadership style based on the MLQ scoring guidelines.

Transformational and transactional leadership styles are preferred in the hospitality industry over a passive leadership style (Williams, Bosselman, Hurst, \& Zheng, 2013). In addition, transformational leadership is more effective when leading groups (Hackett, 2006). When comparing the two groups of sports classifications versus the two effective leadership styles, the chi-square was not significant as shown in Table 3. The insignificant chi-square indicates that chance could explain the relationship between the two. However, both transformational and transactional leaderships can be viewed as beneficial to building cohesive teams. Team sports involve transactions (e.g., athletes are rewarded for individual accolades) made and individuals are inspired to transform behaviors to those that are conducive to overall team objectives (e.g., athletes play different team roles to aggrandize the team) (Calhoun, 2007; Williams et al., 2013). Also, individual and team sports' findings might be the same due to the nature of some individual middle/high school sports (i.e., golf, track); in school, even these individual sports still have an overall team concept or component.

These finding may be relevant to the management of today's intricate hospitality establishments. Hospitality managers are expected to manage environments with high turnover and significant ethnicity and gender differences, among other complexities. These findings suggest that undergraduate hospitality students with a team sport background prefer working in groups and exhibit effective leadership styles with collaborative leadership traits. 
Table 3

Cross-tabulation of Sport Classification and Leadership Style

\begin{tabular}{llll}
\hline \multirow{2}{*}{ Sport classification } & \multicolumn{3}{c}{ Leadership style } \\
\cline { 2 - 4 } & Transformational & Transactional & $X^{2}$ \\
\hline Team & 55 & 16 & $0.044^{*}$ \\
Individual & 28 & 9 & \\
\hline
\end{tabular}

Note. ${ }^{*} p=0.834$.

\section{Conclusions}

The majority of the undergraduate hospitality students in this study played team sports and displayed effective leadership styles that indicate collaborative leadership traits. Collaborative leaders tend to employ interpersonal skills to influence others to embrace internal and external relationships for the benefit of the organization (Chrislip, 2002). Transformational and transactional leaders employ similar tactics to accomplish objectives in the same way as collaborative leaders. Today's hospitality managers are tasked with the responsibility to persuade a diverse working population to align with team goals and objectives (Jackson, 2010). Team sports are structured to teach individuals how to manage and lead others from diverse backgrounds (e.g., different ethnic groups, socio-economic status, cultures) (Brunelle, Danish, \& Forneris, 2007).

Undergraduate hospitality students demonstrated a willingness to work in groups, while successfully leading individuals with collaborative leadership traits derived from transformational and transactional leaderships. This might indicate that individuals can develop a passion to work with others and that passion can lead to advantageous collaborative leadership traits. In team sports, athletes are rewarded for individual and team accomplishments to promote transactional leadership; athletes are empowered with the responsibility to lead others and themselves to establish team goals to assist in the development of transformational leadership (Bass \& Avolio, 2004; Hackett, 2006). Passion is needed in team-oriented endeavors, and team sports provide that passion to individuals who lead others in complex team environments (Calhoun, 2007).

Findings of this study can be used to encourage undergraduate students to participate in college intramural sports (e.g., basketball, flag football, softball) and clubs and organizations (e.g., honor societies, diversity groups, Club Managers Association of America) to garner additional collaborative skills needed as future managers in the hospitality industry. Teamwork is crucial to the establishment of cohesive hospitality work environments, and team members must have the passion and desire to function collectively in hospitality organizations (Jackson, 2010).

Hospitality management curriculums are designed to equip undergraduate students with opportunities to practice leadership styles needed to inspire diverse individuals in the hospitality firms of the future. However, some hospitality curriculums are not structured to give students an opportunity to face practical issues impeding the success of hospitality establishments. Participation in team sports offers athletes opportunities to think in a rational and critical manner within unstructured sporting events; this aids in the maturation of beneficial leadership skills and traits that are needed to manage constantly evolving work environments.

Hospitality management programs should implement real-life case scenarios that constantly group students in teams within the parameters of a class, minus the pressure of a grade. White and Fantone (2010) found that pass-fail grading supports collaboration in groups and increases intrinsic motivation for second-year medical students. When a grade is utilized, students might focus on completing the group work for the letter 
grade rather than their development of collaborative leadership skills. Sports provide a buffer, because passion and collaborative skills are involved, not a grade. During hospitality leadership courses, professors can take students outside the class for group work. For example, students can be divided into bowling teams and then discuss as a class the collaborative leadership skills learned from the experience with oral presentations or writing assignments. Innovative teaching methods are needed to prepare successful students to be productive hospitality managers in the future, and lessons learned from team sports can contribute to collaborative leadership traits.

\section{References}

Altinay, L. (2010). Market orientation of small ethnic minority-owned hospitality firms. International Journal of Hospitality Management, 29(1), 148-156.

Arthur-Banning, S., Wells, M., Baker, B., \& Hegreness, R. (2009). Parents behaving badly? The relationship between the sportsmanship behaviors of adults and athletes in youth basketball games. Journal of Sport Behavior, 32(1), 3-18.

Assegid, Y. (2009). What sets true leaders apart? Integral Leadership Review, 9(5), 1-11.

Bass, B. M., \& Avolio, B. J. (2004). Multifactor leadership questionnaire (3rd ed.). Menlo Park, C.A.: Mind Garden.

Brunelle, J., Danish, S. J., \& Forneris, T. (2007). The impact of a sports-based life skill program on adolescent prosocial values. Applied Developmental Science, 11(1), 43-55.

Brymer, R. A., Wilborn, L. R., \& Schmidgall, R. S. (2006). Future global hospitality leaders: A comparison of European and US ethics. International Journal of Contemporary Hospitality Management, 18(7), 546-553.

Calhoun, J. (2007). A passion to lead: Seven leadership secrets for success in business, sports, and life. New York, N.Y.: St. Martin's Griffin.

Chelladurai, P. (1980). Leadership: Handbook on research on sport psychology. New York, N.Y.: McMillian.

Chelladurai, P., \& Carron, A. V. (1983). Athletic maturity and preferred leadership. Journal of Sport Psychology, 5(2), $371-380$.

Chrislip, D. (2002). The collaborative leadership field book-A guide for citizens and civic leaders. San Francisco: Josey Bass.

Dillman, D. A. (2007). Mail and internet surveys. The tailored design method 2007 update with new Internet, visual, and mixed-mode guide (2nd ed.). New York, N.Y.: John Wiley \& Sons.

Hackett, R. (2006). Bringing out the best. Canadian Business, 79(12), 73-74.

Hinckley, P. (2009). Making change work. American School Board Journal, 196(3), 27-28.

Horton, B., Foucar-Szocki, R., \& Clark, I. (2009). Meyers Briggs type indicator and academic performance in hospitality education. Journal of Hospitality and Tourism Education, 21(4), 55-64.

International Council on Hotel, Restaurant, and Institutional Education. (2011). Guide to college programs in hospitality, tourism, \& culinary arts. Retrieved from http://www.guidetocollegeprograms.org/institution_search_map.php?fed= US\%20Central\%20Federation\&country=\&degree_typey=any\&term=

Iun, J., \& Huang, X. (2007). How to motivate your older employees to excel? The impact of commitment on older employees' performance in the hospitality industry. International Journal of Hospitality Management, 26(4), 783-806.

Jackson, L. A. (2010). Enterprise resource planning systems: Revolutionizing lodging human resource management. Worldwide Hospitality and Tourism Themes, 2(1), 20-29.

Latham, J., \& Vinyard, J. (2004). Baldrige user's guide: Organization diagnosis, design, and transformation. New York, N.Y.: John Wiley \& Sons.

Lee, C., \& Way, K. (2010). Individual employment characteristics of hotel employees that play a role in employee satisfaction and work retention. International Journal of Hospitality Management, 29(3), 344-353.

Manos, K. (2006). 101 ways to motivate athletes. Monterey, C.A.: Coaches Choices.

Maon, F., Lindgreen, A., \& Swaen, V. (2009). Designing and implementing corporate social responsibility: An integrative framework grounded in theory and practice. Journal of Business Ethics, 87(1), 71-89.

National Center for Education Statistics. (2011). Fast facts. Retrieved from http://nces.ed.gov/fastfacts/display.asp?id=98

Nonaka, I., \& Nishiguichi, T. (2001). Knowledge emergence. New York, N.Y.: Oxford University Press.

Organization of Eastern Caribbean States. (2008). Youth leadership in sports. Retrieved from http://www.oecssecretariat.org/sports\%20desk/articles/YouthLeadership.php

Pudlowski, E. (2009). Managing human resource cost in a declining economic environment. Benefits Quarterly, 25(4), 37-43. 
Ross, G. F. (1995). Management-employee divergences among hospitality industry employee service quality ideals. International Journal of Hospitality Management, 14(1), 11-24.

Seefelt, V. D., Ewing, M. E., \& Brown, T. (1996). Youth sports in America: An overview. PCPFS Research Digest, 2(11), 51-63. Stein, L. (2009). Lead students—Don’t just manage them. Phi Delta Kappan, 91(4), 82-86.

Sugar, W., \& Holloman, H. (2009). Technology leaders wanted: Acknowledging the leadership role of a technology coordinator. TechTrends: Linking Research and Practice to Improve Learning, 53(6), 66-75.

White, C. B., \& Fantone, J. C. (2010). Pass-fail grading: Laying the foundation for self-regulated learning. Advances in Health Science Education, 15(4), 469-477.

Williams, J., Bosselman, R., Hurst, J., \& Zheng, T. (2013). Passive leadership is unlikely among hospitality managers with high-level youth sports participation. Journal of Hospitality and Tourism Education, 25(1), 22-28. 